\title{
EDITORIAL
}

\section{El malestar de la política}

\section{Consejo de Redacción}

Palabras clave: política, elecciones, gobernanza, público/privado, ideologías, autonomías.

Key words: politics, elections, governance, public/private, ideologies, autonomies.

Fieles a nuestra línea editorial, la Revista de Fomento Social suele ofrecer a sus lectores algún tipo de reflexión colectiva con ocasión de la celebración periódica de elecciones generales'. En esta ocasión, más allá de los análisis de los resultados y de las implicaciones políticas de los comicios del 9 de marzo de 2008 -por otro lado ya muy abundantes y conocidos- hemos optado por ofrecer a nuestros lectores una reflexión surgida de la sensación compartida por los miembros de nuestro Consejo de Redacción de lo que hemos expresado en el título como "malestar" de la política².

En consecuencia, dedicamos unos primeros apartados a describir lo que llamamos "conflictividad bipolar" sin duda existente en España, así como a sus causas y sus consecuencias. A continuación reflexionamos brevemente sobre la sensación

1 De algunas de las convocatorias a elecciones generales nos hemos ocupado. Por ejemplo: CONSEJO DE REDACCIÓn (1999), "Las elecciones del 13 de junio: ¿¿Qué modelo de democracia?", Revista de Fomento Social, n 214, abril-junio, 161-176; CONSEJO de ReDACCIÓN (2004), "Dos días de marzo", Revista de Fomento Social, $\mathrm{n}^{\circ}$ 233, enero-marzo, 11-12.

${ }^{2}$ Como en otras ocasiones, la elaboración de este editorial tuvo como punto de partida una sesión de seminario de los miembros del Consejo de Redacción y otros invitados. Actuó como ponente el Prof. Antonio Porras Nadales, Catedrático de Derecho Constitucional de la Universidad de Sevilla, quien posteriormente redactó un primer borrador del texto. 
creciente de vacío ideológico del debate político así como sobre un tema al que somos particularmente sensibles en España, cual es el debate territorial. Nos ocuparemos también con brevedad del aparentemente fracasado recurso a lo que se ha llamado en algunos círculos modelo de "gobernanza" como alternativa a la "política politizada". Al final enumeraremos algunas tareas que, en consecuencia, quedan pendientes.

\section{Un diagnóstico general: el incremento de la conflictividad bipolar}

En efecto, los resultados de las elecciones generales de marzo de 2008 en España parecen responder, más allá de los detalles concretos, a una pauta general según la cual evolucionan las democracias europeas: en efecto, es posible constatar sustanciales coincidencias en nuestras elecciones de marzo y las desarrolladas anteriormente en Francia o con posterioridad en Italia. Nos referimos a la progresiva consolidación del bipartidismo, que implica una tendencia hacia la bipolarización del proceso político. Tal tendencia no parece, en principio, consecuencia ineludible del sistema electoral, sino más bien resultado de todo un conjunto de factores que estarían debilitando el pluralismo competitivo e intensificando paralelamente la conflictividad política.

Por lo que afecta a España, el fenómeno parece representar una sustancial alteración de las pautas históricas desarrolladas durante la etapa de la transición, cuando la trascendencia del consenso como marco de referencia general para la acción política parecía inspirar una dinámica política de menor tensión, basada en la existencia de grandes acuerdos entre las principales fuerzas políticas sobre los asuntos "de Estado" y en el desarrollo de una cultura de diálogo y de respeto al pluralismo.

Esta experiencia española no fue exclusiva de nuestro país en un momento tan trascendental como fue la transición. Constituyó también para las restantes democracias europeas un momento histórico singular, característico de las primeras etapas de desarrollo del Estado de bienestar tras la segunda posguerra: un momento en que las inercias conflictuales de las etapas históricas anteriores parecieron atenuarse en aras de unos objetivos comunes y en un marco de diálogo y consenso social, que hizo posible la eclosión y posterior consolidación del Estado social en Europa. La propia noción de democracia "consociacional", desarrollada por A. Lijphart a finales de los años 1960, aparecía como un modelo más apto para el desenvolvi- 
miento de la competencia política, puesto que implicaba una relativa atenuación de la conflictividad y una apuesta decidida por el diálogo y la búsqueda de puntos de encuentro entre las distintas fuerzas políticas.

La crisis de la democracia consociacional, como la crisis del centrismo en España, constituye un giro paradójico: la emergencia de una bipolarización política que, sin embargo, no parece coincidir con una paralela polarización de la sociedad; responde más bien a una intensificación de la competencia por la conquista del voto mayoritario, situado en el centro del espectro ideológico. Estamos, pues, ante un fenómeno inducido por la oferta política y no generado por la propia demanda social.

Esta tendencia a la bipolarización es, eso, tendencia. En algunos países europeos (Alemania, por ejemplo) un tercer partido (partido bisagra) ha sido determinante para formar gobierno. En España, ese papel ha querido ser asumido por Izquierda Unida, pero su evolución reciente más bien se caracteriza por una progresiva pérdida de peso político (la última prueba, los malos resultados obtenidos en marzo). Más importancia han tenido en este sentido los partidos nacionalistas que, en varias legislaturas, han apoyado al gobierno central, pero $\dot{\iota}^{\text {no }}$ es esto reflejo de la peculiaridad de nuestro mapa autonómico más que de la evolución de las grandes tendencias políticas? Cabría hablar quizás entonces en España de un bipartidismo atenuado ${ }^{3}$. Pero no creemos que esto invalide la descripción más general que hemos hecho ni las consideraciones que siguen.

\section{Sus posibles causas}

Por eso, cuando se trata de indagar en las causas de esta intensificación de la conflictividad bipolar, que marca una nueva etapa en la evolución histórica de las democracias europeas, la primera constatación debe ser que se trata de un fenómeno propio o exclusivo de la esfera política. No existen en el medio social o económico factores que expliquen un mayor enfrentamiento entre sectores o colectivos sociales, ni hay nuevas claves ideológicas que conduzcan hacia una

\footnotetext{
${ }^{3}$ Merece la pena señalar cómo las dos veces que el PSOE ha llegado al poder en España desde la oposición han coincidido con acontecimientos de cierto dramatismo para nuestro país (el golpe de Estado de 1981 y el atentado en Madrid de 11 marzo 2004). Estas circunstancias provocaron en cierto sobredimensionamiento del poder que el partido llegó a alcanzar en ambos momentos iniciales de su mandato.
} 
intensificación de la competitividad, ni aparecen amenazas exteriores o factores socioeconómicos que impongan diferencias radicales entre las distintas fuerzas políticas susceptibles de acentuar el grado de conflictividad del sistema.

Da la impresión, por tanto, que la intensificación conflictual constituye más bien un elemento al servicio de la propia competencia partidista, es decir, de la pura lucha por el poder. Y para este endurecimiento del conflicto se cuenta además con el decisivo apoyo de los medios.

En efecto, los mass media han terminado por convertirse en la gran arena donde se desarrolla el espectáculo de la competencia política, hasta el punto de condicionar y afectar a sus principales estrategias. Ello explica seguramente la tendencia hacia una progresiva reducción de los contrincantes (y por lo tanto del pluralismo) hasta llegar a un enfrentamiento entre dos que reproduce las claves de cualquier competición deportiva. Y con otro efecto añadido: la tendencia al reforzamiento de la personalización del proceso político. El discurso político reflejado en los medios va quedando cada vez mas despojado de cualquier elemento de racionalidad reflexiva hasta convertirse en un mero vehículo destinado a proyectar tomas de postura diferenciadas, cada vez más alejadas de todo punto de encuentro o espacio de consenso. La progresiva simplificación del discurso político, que trae consigo el fenómeno de la denominada "videopolítica", conduce así a una intensificación de las diferencias, en el fondo quizás artificial e inducida. Es la lógica del marketing, al estilo de las grandes marcas comerciales cuando emplean técnicas más o menos sofisticadas para asegurarse la conquista de cuotas crecientes de mercado.

De este modo los propios comunicadores o agentes de opinión acaban convirtiéndose en apéndices de las respectivas fuerzas políticas, y la dinámica mediática termina transformándose en una auténtica jungla donde merodean esas "fieras salvajes" a las que se refirió Tony Blair en su discurso de retirada de la vida política. Puestas así las cosas, el enfrentamiento y el conflicto apenas dejan espacio para localizar puntos de encuentro: más bien se favorece un creciente maniqueísmo que corre el riesgo de acabar arrastrando también a los propios ciudadanos.

Este protagonismo de los elementos mediáticos contribuye adicionalmente a generar riesgos difusos de captura entre la esfera de los mass media y la propia esfera política: la primera, apoyada por grandes empresas de comunicación, mientras que la segunda está integrada por unos partidos con falta de recursos financieros y con unos circuitos de financiación nunca suficientemente transparentes. El resultado de todo ello no puede ser más que un progresivo enrarecimiento del marco competitivo general donde se desenvuelve el pluralismo políitico. 
Esta proyección audiovisual y esta progresiva dimensión virtual del conflicto político conducen a reforzar las posiciones de los sectores más radicales o minorías activas, los cuales actúan a modo de core supporters como defensores incondicionales de la propia marca. Al mismo tiempo, quedan condenadas a la marginación tanto las mayorías silenciosas como los sectores con algún tipo de conocimiento crítico e independiente. El recurso a las manifestaciones y la estrategia de ocupar la calle como un ariete de la alternancia sustituye así al debate racional y a la defensa argumentativa de las propias ideas.

Esta orientación a la "videopolítica" condiciona también los propios contenidos de la agenda pública: los temas se priorizan o se ocultan según su mayor o menor grado de espectacularidad e interés mediático. No es raro entonces que se marginen los aspectos más sustanciales del debate político. De este modo, los temas más objetivamente problemáticos de la realidad política pueden ser relegados frente a la cuota de pantalla conquistada por asuntos de mayor espectacularidad mediática. La política se acaba configurando como una pura realidad virtual.

\section{Sus consecuencias}

La emergencia de un nuevo bipartidismo podría ser interpretada en principio como un simple retorno hacia un sistema de partidos dotado de una vieja y larga trayectoria histórica, particularmente en el universo anglosajón (un modelo que fue defendido hace algún tiempo a nivel teórico por prestigiosos autores, como el francés Duverger). Sin embargo, en el contexto contemporáneo, esta dinámica de bipolarización no contribuye a reforzar las exigencias de una mayor calidad democrática ni responde a las promesas pendientes de una teórica "democracia avanzada" propia de los albores del siglo XXI.

Primera consecuencia de esta bipolarización es la pérdida progresiva de las necesarias claves de consenso social que exige todo sistema democrático y el consiguiente riesgo de pérdida de los valores tradicionales propios del Estado del bienestar, como la solidaridad o la igualdad. Esta falta de grandes consensos se percibe con acuciante intensidad en el caso español en ámbitos tan decisivos como la política territorial o la educativa, llegando incluso a generar un peligroso incremento del grado de politización de esferas institucionales independientes, como el Tribunal Constitucional, el Consejo General del Poder Judicial o determinadas agencias regulativas, hasta el punto de producir auténticos bloqueos en asuntos de especial relevancia. Al mismo tiempo, iniciativas aparentemente neutrales, como 
la recuperación de la memoria histórica o la introducción en el sistema educativo de nuevas asignaturas de formación ciudadana, pueden acabar convirtiéndose en instrumentos al servicio de esa progresiva bipolarización inducida desde la esfera política.

Otra consecuencia no sólo teórica de esta bipolarización sería incluso la tendencia a concebir la propia acción de gobierno como una especie de campaña electoral permanente. Las políticas públicas se priorizan según su potencial rentabilidad electoral y la agenda del gobierno tiende a sesgarse según las exigencias coyunturales de la política partidista y su cobertura mediática. Es este un ambiente que preludia la generalización de estrategias clientelares y la progresiva colonización por parte de la esfera política de ámbitos sociales o institucionales tradicionalmente autónomos.

Más aún, en la propia evolución del modelo de "Estado de partidos", esta dinámica conflictual puede modificar la noción misma de "partidos": éstos dejan de ser sujetos de un juego cuyas reglas son compartidas por todos para volver a lo que fueron originariamente, meras "facciones" enfrentadas (siguiendo la doctrina formulada en su momento por G. Sartori en su Partidos y sistemas de partidos). Pero por este camino lo que se produce es una auténtica regresión en términos históricos, cuyos efectos son fáciles de percibir: esa decadencia de nuestra clase política, en calidad y en formación, que parece educada en un tipo de "cultura" partidista cuyo único aprendizaje se orienta a la supervivencia en un contexto competitivo descontrolado. Igualmente se observa un progresivo enrarecimiento de los procesos de alternancia que, en teoría, deberían constituir un elemento normalizado del funcionamiento del sistema democrático.

En resumen, parece que un sistema constitucional como el español, nacido en un contexto histórico de tipo consensual, donde se trataba de superar las lacras históricas del siglo XX, presenta notables dificultades para adaptarse adecuadamente a un contexto de intensificación desenfrenada de la competencia y la tensión bipartidista.

\section{La relativa vaciedad de las ideologías}

Este proceso de degradación de la esfera política que venimos analizando tampoco parece que pueda encontrar su justificación en claves ideológicas suficientemente diferenciadas. Más bien asistimos a un fenómeno de signo contrario: la progresi- 
va desideologización que vienen experimentando los partidos políticos desde la emergencia y el desarrollo del modelo denominado "partido catch all": el éxito de este tipo de partido se debe a que parece el modelo dotado de una mejor competitividad electoral en el contexto contemporáneo. Ello se debe a varios rasgos que los caracterizan y que les dota de un fuerte potencial electoralista: el fuerte liderazgo, la gran capacidad de proyección a través de los media, su capacidad de atraer a cualquier segmento del electorado apoyándose en unos perfiles ideológicos difusos y en propuestas atractivas ante la ciudadanía.

Ante este tipo de partido, las tradicionales nociones de izquierda y derecha apenas tienen otra significación que la que les otorga la retórica políitica. En efecto, sabemos que las grandes decisiones de política económica están en la actualidad muy condicionadas tanto por el marco de la Unión Europea como por el proceso de la globalización. Sólo en las políiticas sociales es posible constatar, al menos en España, diferencias de cierta importancia que sirven de motivación para que muchos votantes opten por un partido $v$ otro. Y tampoco podemos olvidar a aquellos votantes que se mantienen fieles a un mismo partido por razones ideológicas relacionadas con frecuencia con tradiciones familiares. Más aún, no se puede decir que, a la hora de decidir el voto, haya desaparecido ya del todo el espectro de aquel tradicional conflicto entre ricos y pobres que de forma tan rotunda y determinante se manifestó durante la primera mitad del siglo XX. Pero todo eso no es suficiente para negar que las nociones de derecha o izquierda no tienen ya hoy la fuerza que tuvieron en otro tiempo, de modo que difícilmente bastan por sí mismas para explicar esa bipolarización políitica que hemos venido constatando.

Algunos teóricos recurren a la contraposición entre "liberalismo" y "republicanismo" como clave para explicar la división ideológica contemporánea. Nosotros no acabamos de ver el valor heurístico de tal recurso; tampoco nos parece que esas dos corrientes de pensamiento tengan una gran capacidad de atracción para la mayor parte de la sociedad. En efecto, si por liberalismo entendemos una defensa de los tradicionales derechos de libertad, resulta difícil concebir que alguna fuerza política pueda renunciar en el contexto contemporáneo a lo que constituye en rigor un bagaje de la propia civilización occidental; y si el republicanismo lo identificamos con la defensa de los valores cívicos y de la nueva noción de "ciudadanía", debemos reconocer en seguida que estos conceptos constituyen más bien pautas de cultura política, pero que difícilmente pueden convertirse en argumentos movilizadores al servicio de una causa colectiva. Es más, junto a esta contraposición de liberales y republicanos no deberíamos olvidar que existen entre nosotros ciertos componentes de tipo "comunitarista": el comunitarismo subraya la existencia de identidades diferenciadas, que se concretan en pautas culturales esenciales para la 
cohesión de una colectividad, pero que pueden acabar derivando en particularismos patológicos y erigirse en obstáculo para un desarrollo social cosmopolita.

También habría que decir una palabra sobre los denominados "nuevos movimientos sociales". Indudablemente han aportado elementos nuevos de alcance tanto práctico como ideológico, pero no han conseguido configurarse como auténticas plataformas ideológicas susceptibles de generar concepciones globales del mundo dotadas de una cierta capacidad movilizadora. Ni siquiera el más significativo de todos ellos, el ecologismo, con algunas brillantes plataformas como la orquestada recientemente por Al Gore en torno a los riesgos del cambio climático, puede considerarse en rigor como un soporte ideológico capaz de explicar la dinámica social y política de las democracias contemporáneas.

\section{El debilitamiento del modelo Estado-nación}

Otra clave a la que algunos recurren para explicar esta intensa transformación del marco político de las democracias occidentales estaría relacionada con el resquebrajamiento del modelo de Estado-nación. Sabemos cómo éste se configuró a lo largo de los últimos siglos y cómo se reforzó más recientemente, durante el periodo de posguerra, al desarrollarse el Estado de bienestar, con sus fuertes dosis de intervencionismo y de centralización de la acción política.

Si hoy hablamos de resquebrajamiento, es para referirnos a lo que está ocurriendo especialmente en Europa, y que se concreta en un doble proceso simultáneo: por una parte, de desbordamiento hacia fuera de las tradicionales fronteras estatales; por otra, de reordenación interior del mismo, siguiendo las pautas que impulsan el regionalismo, el desarrollo autonómico, la devolution, etc.

Sin embargo, tal transformación territorial no parece haber permitido a las nuevas esferas institucionales desprenderse de los lastres partitocráticos. Asílo comprobamos cotidianamente en España, donde las "posiciones" de las distintas Comunidades Autónomas ante asuntos de Estado responden más bien a los alineamientos a favor o en contra del partido que en cada momento esté en el gobierno. Por otra parte, este nuevo marco de complejidad territorial exige todo un entramado de mecanismos de cooperación (en torno al ideal de la denominada "gobernanza multinivel"), cuyo desarrollo efectivo está muy lejos de ser satisfactorio. Más bien hay síntomas de una cierta "refeudalización" del sistema: en efecto, tras un desfasado debate sobre supuestas identidades colectivas, que a muchos resulta ficticio, 
parecen ocultarse fenómenos como un cierto clientelismo, amparado en el desarrollo de las burocracias administrativas, o un reforzamiento de los nuevos egoísmos colectivos, el mayor obstáculo para el desarrollo efectivo del valor solidaridad o de la dimensión cosmopolita.

Cabría considerar que estas dificultades del proceso territorial no son más que algo meramente transitorio si, al menos en Europa, confiásemos en la capacidad de las instituciones centrales de Bruselas para desarrollar un liderazgo efectivo. Pero el fracaso del Tratado Constitucional Europeo y el más reciente e inesperado "no" irlandés al Tratado de Lisboa ${ }^{4}$ son dos escenarios que apenas permiten abrigar serias esperanzas de esta capacidad de liderazgo.

\section{La difícil "despolitización” de la política: la "gobernanza" como alternativa}

Entre las posibles vías de salida de esta compleja problemática otros apuestan por un desplazamiento de los circuitos decisionales desde la esfera estrictamente político-partitocrática hacia el ámbito de una gestión pública profesionalizada: en ella tendrían un protagonismo especial los expertos pero se incorporarían también circuitos participativos, valiéndose incluso de técnicas de gestión tomadas de la empresa privada. En teoría, pues, esta moderna noción de gobernanza supondría un desplazamiento del eje articulador de la acción pública: pasaría de la tradicional esfera de la "política" a los ámbitos sectoriales y específicos de las distintas "políticas públicas".

La categoría de gobernanza ha ganado un prestigio indudable a partir del Libro Blanco de la Gobernanza Europea de $2001^{5}$. La gobernanza implica la configuración de todo un sistema de redes donde se integrarían las distintas esferas institucionales relativamente autónomas que conforman la realidad (como mínimo en la escala local, regional, estatal y europea), operando a través de procesos de cooperación y coordinación tanto en el plano horizontal como en la escala

\footnotetext{
${ }^{4}$ Véase a este respecto nuestro anterior editorial: CONSEJO DE REDACCIÓN (2008), "La Constitución Europea renace de sus cenizas: el Tratado de Lisboa", Revista de Fomento Social, n 249, enero-marzo, 31-61.

5 "La gobernanza global - Un libro blanco", publicado en el Diario Oficial de las Comunidades Europeas de 12 octubre 2001, COM (2001) 428 final.
} 
multinivel. Ahora bien, el desarrollo efectivo de la gobernanza exige otorgar a las instituciones y agencias encargadas de la gestión pública un cierto grado de autonomía, y éste sólo puede lograrse a condición de que la propia esfera política se autolimite. Paradójicamente asistimos más bien al proceso contrario: a una creciente colonización política de las instituciones y de las esferas burocráticas, que no ha hecho posible la puesta en marcha de los procesos de reforma de la administración necesarios para su desarrollo efectivo, al menos en el contexto español ${ }^{6}$.Por esta razón la noción de gobernanza, más allá de su dimensión teórica - meramente "heurística", acaba transformándose en un puro recurso retórico tras el que se esconde frecuentemente una tendencia a crear esferas de gestión autónoma, dotadas de una autonomía en el fondo bastante ficticia. Es cierto que existen algunas contadas experiencias positivas, pero no son suficientes para modificar esa inercia derivada del alto grado de politización del sistema, y que coexiste con modelos organizativos que a comienzos del siglo XXI deberíamos considerar ya como obsoletos.

\section{Tareas pendientes y propuestas}

Todo lo dicho justifica que hayamos hablado en el epígrafe de este editorial de malestar de la política. El resultado de todo ello es que los grandes asuntos pendientes que, a comienzos del siglo XXI, deberían constituir la agenda prioritaria para las instituciones públicas, se ven condenados al silencio: desde el diagnóstico sobre los instrumentos más eficientes para acabar con la pobreza hasta las respuestas a los llamados "Estados fallidos" y la recomposición de un diálogo efectivo Norte-Sur; desde el debate sobre los bienes públicos globales hasta la reformulación de un desarrollo social y económico que resulte sostenible; y sin olvidar los gigantescos retos planteados por la creciente demanda energética o las dificultades que atraviesa el aprovisionamiento de alimentos a escala mundial.

\footnotetext{
${ }^{6}$ En Andalucía tenemos un ejemplo interesante en esta dirección, que no ha dado los frutos deseados. La Junta de Andalucía aprobó en 2003 un documento "Andalucía segunda modernización. Estrategias y propuestas" que fue el resultado de la tarea de una serie de comisiones de trabajo. Véase: CONSEJO DE REDACCIÓN (2002), "Nuevas tecnologías y cambio económico: interrogantes a propósito de la segunda mdernización", Revista de Fomento Social, n 226, abril-junio, 219-240; A. PorRas NAdales (2005), "La reforma de la administración andaluza y los desafíos de la segunda modernización", Revista de Fomento Social, $n^{\circ} 239$, julio-septiembre, 463-490. Una propuesta digna de mención fue la creación de agencias públicas prestadoras de servicios en la línea del Servicio Andaluz de Salud: esta iniciativa, que hubiera representado una importante reforma de la administración andaluza, no ha tenido hasta ahora ninguna concreción práctica.
} 
La globalización plantea problemas y desafíos que apenas encuentran eco en el discurso de la competencia político-partidista; son problemas y desafíos que sólo ocupan la atención que merecen en foros de dimensión internacional, desgraciadamente dotados de escasa efectividad real.

Mientras tanto la tradicional esfera política, inmersa en su laberinto mediático y en su propia dinámica competitiva, parece ir a remolque de los grandes problemas, improvisando respuestas precarias o puramente retóricas. Al final, el paradigma de la no-acción se convierte paradójicamente en la principal expresión de la capacidad de respuesta gubernamental; todo ello ante la perplejidad colectiva y la ausencia de un compromiso efectivo con la política por parte de los ciudadanos. No quisiéramos que este editorial dejase en el lector un sabor de amargo pesimismo. Por eso acabaremos reiterando los llamamientos a esas reformas, que vemos no llegan, de momento, a concretarse. Sobre todas ellas se discute continuamente, pero es un debate estéril que entretiene a los políticos sin llevarles a resolver ninguna de esas graves cuestiones pendientes:

A nivel de grandes instituciones del Estado se ha hablado muchas veces de la reforma de la Constitución, de la reforma del Senado o de las reformas estatutarias de las Comunidades Autónomas.

La ley electoral está necesitada de una revisión que incorpore la experiencia de estas tres décadas de vigencia. Las listas cerradas suscitan no pocas críticas; las listas abiertas exigirían ser sometidas a un análisis riguroso para detectar sus ventajas e inconvenientes. En todo caso, esta cuestión estaría estrechamente ligada a la de las dimensiones de la circunscripción electoral.

Los partidos siguen siendo hoy un cauce importante de acción pública, pero están exigiendo una revisión en muchos niveles: su funcionamiento interno y el sistema de financiación requieren una atención especial, porque son aspectos no sólo formales sino esenciales para determinar la cultura política que los anima por dentro y que inspira a sus militantes.

La acción pública no puede quedar relegada a la acción política partidista. Esto es cada vez más claro a medida que se constatan las deficiencias de una sociedad cada vez más ausente de la política y más escéptica respecto a sus posibilidades. En este sentido la apuesta del republicanismo debería inspirar muchas redes y formas de organización donde no se establezca una separación tan tajante entre 
esfera política/partidista y esfera privada ${ }^{7}$. Pero también aquí hay una cuestión de cultura política y ciudadana que merece nuestra atención.

En efecto el desarrollo de esta cultura política y ciudadana debería ser una preocupación de todos. Y habría de tener una relevancia especial en todos los ámbitos educativos. Cabría aquí hablar de una "amistad cívica" (lo ha hecho recientemente Adela Cortina, inspirándose en Aristóteles ${ }^{8}$ ) o de "amistad fraterna" (al estilo de Maritain). En un caso y otro se trata de superar la dialéctica amigo/enemigo, que tanto orienta nuestras relaciones sociales, haciendo descubrir que todos estamos interpelados por la construcción del bien común y por el mantenimiento de un orden global de convivencia compartido.

Esa mayor articulación de las distintas esferas pública y privada, a la que nos referíamos antes, contribuiría además a sanear la vida política, no sólo apoyando una más enérgica lucha contra la corrupción y el clientelismo (tareas inaplazables), sino creando las condiciones para que estas prácticas no encuentren el terreno abonado para su desarrollo.Como se ve, no estamos proponiendo grandes innovaciones. Pretendemos sólo ser coherentes con ciertas lecciones de nuestra experiencia occidental de democracia, también de la experiencia más particular de nuestro país en las últimas tres décadas. El abordarlas de forma rigurosa podría contribuir además a devolver el prestigio perdido a la clase política. Porque ¿̇no es cierto que estamos asistiendo a un desprestigio de la clase política al tiempo que la clase empresarial gana en consideración social? ¿ ¿no es preocupante que en las sociedades contemporáneas (y la española no es excepción) falten personalidades políticas capaces de convertirse en modelos de identificación y testimonios atractivos para quienes se plantean alguna vez su vocación política?Más aún estas tareas sólo podrán abordarse desde un maduro sentido de la gradualidad. Es un criterio elemental de realismo ante la complejidad de la vida social y política. En este campo hay que estar siempre preparados para luchar por la justicia sometiéndose simultáneamente a la ley del tiempo: aceptar que ni la erradicación definitiva del mal ni el triunfo absoluto del bien son posibles y que no nos queda más opción que aprender a convivir con lo complejo y lo impuro. Pero este reconocimiento de la gradualidad no significa resignación ante ese "malestar" de la política al que hemos dedicado estas páginas. Precisamente lo que las tareas propuestas quieren

\footnotetext{
${ }^{7}$ Sobre la complejidad del par público/privado puede verse: X. ETXEBERRIA (2007), "La vida pública, sus agentes y sus referentes éticos", Revista de Fomento Social, $\mathrm{n}^{\circ}$ 248, octubre-diciembre, 538-554. Este número de nuestra revista está dedicado casi enteramente a "Ética de la vida pública".

${ }^{8}$ Cf. A. Cortina (2008), "Amistad cívica", El País, 6 mayo.
} 
ofrecer es alguna salida a ese "malestar". Y es que estamos convencidos de que, a pesar de todas sus deficiencias, la democracia ha contribuido a consolidar durante los últimos siglos el proceso de civilización de la humanidad. En realidad lo que está siempre en juego es la defensa y promoción de los derechos humanos como categoría o valor fundamental para la convivencia. Pero esto exige algo más que ciudadanos pasivos que se sienten sujetos de derechos. Exige el desarrollo colectivo de todo ese conjunto de virtudes cívicas que estuvieron en el origen de los procesos democráticos históricos y que hacen de las personas no sólo beneficiarias sino también artífices del bienestar de todos. Y eso, en el marco abierto y cosmopolita constituido por la sociedad del siglo XXI. 